\title{
INCIDENCE AND EXTENT OF CANCER TREATEMENT RELATED CARDIOTOXICITY OF BREAST CANCER PATIENTS
}

\author{
EL -KHASHAB KAE ${ }^{(1)}$, Ramadan AH ${ }^{(2)}$, GHAREEB HS $^{(3)}$
}

(1) Khalid Elkhashab, Professor and head of cardiology department ,faculty of medicine, fayoum university.

(2) Asmaa Ramadan, Cardiology department, faculty of medicine fayoum university.

(3) Haytham Soliman, lecturer of cardiology, Department of cardiology faculty of medicine fayoum university

\section{ABSTRACT;}

Breast treatment has evolved rapidly, resulting in over $90 \%$ survivals, making breast cancer survivors the largest cancer survivorship group. As a result of common risk factors, the effects of chemotherapy and radiation, and shared genetic and environmental impact on both diseases, a greater risk of cardiovascular disease in these women is observed when compared to the general population.

the acute and long-term consequences of cardiac toxicity on treatment risk-to-benefit ratio, survivorship issues, and competing causes of mortality are beginning to be increasingly acknowledged. As reviewed here, there are multiple diagnostic tools, utilizing both imaging and biomarkers, is ideal in accurately detecting subclinical Left ventricular dysfunction induced by cardiotoxic cancer therapy. While advances in imaging technology have allowed for more precise assessment of cardiac function, the results of the present study showed that the Left
Ventricular GLS was an excellent predictor of cardiotoxicity in our population, with high efficacy for its early diagnosis. cancer patients have the potential to benefit from earlier detection of cardiotoxicity and intervention, allowing them to potentially continue with lifesaving treatments.

The aim of this work is to define Cardiotoxicity of breast cancer therapy clinically and by different imaging modalities.

\section{INTRODUCTION}

Breast cancer is the most common malignancy in women. However, earlier detection and advances in adjuvant therapy have resulted in steadily decreasing rates of breast cancer-related death ${ }^{1}$. There are a million survivors of breast cancer, as such, breast cancer patients are living longer and thus are increasingly at risk for the late-occurring adverse effects of cancer therapy. Most notably, breast cancer survivors are at increased risk for cardiovascular 
disease (CVD) especially left ventricular (LV) dysfunction. Treatment for breast cancer varies depending on multiple tumor-specific factors including size, lymph node involvement, presence or absence of distant metastasis, hormone receptor status, and Human Epidermal Growth Factor Receptor 2(HER2-receptor) status $^{2}$. Taking into consideration these factors, treatment generally utilizes a multimodality approach of surgery, systemic therapy (e.g. chemotherapy, targeted therapy, or endocrine therapy), and radiotherapy. Patient-specific factors and other co morbidities are then taken into consideration in determining the optimal treatment regimen.

Although anticancer drugs are cardiotoxic to various degrees, most attention focuses on anthracyclines especially doxorubicin and on trastuzumab $^{3,4}$. Their cardiotoxic effects can be potentiated by adjunctive chest irradiation ${ }^{5}$. Anthracyclines and trastuzumab act synergistically when co-prescribed to damage the heart, but in different ways.

Beyond the risk of clinical HF, a substantial fraction of patients experience asymptomatic changes in LV ejection fraction (LVEF) with chemotherapy ${ }^{6}$. These clinically silent but measurable drops in LVEF have been seen in patients receiving anthracyclines or trastuzumab ${ }^{7,8}$.
The definition of asymptomatic LV systolic dysfunction varies according to studies. The most commonly accepted definition of decreased LVEF in the oncology community is an absolute 10 points decrease in LVEF from baseline or an LVEF < $50 \%$.

\section{KEY WORDS;}

Chemotherapy, cardiotoxicity is reduction in Left Ventricular EF $>10 \%$ to $<50 \%$ ).

Subclinical LV dysfunction, defined as $>15 \%$ reduction in 2Dimension Global Longitudinal Strain (2D GLS).

\section{PATIENT AND METHODS;}

This prospective observational study included 100 breast cancer patients presenting to oncology department of fayoum University Hospitals. The study was carried out over a period of one year from November 2017 until November 2018.

Patients with breast cancer who early diagnosed or will be treated by chemotherapy or anti-cancer treatment ,aged $\geq 18$ years old had included in this study. Patients with history of a pre-chemotherapy LV dysfunction were excluded. All patients were subjected to: 
1- Routine clinical history and physical examination: With emphasis on: age ,gender, base line risk factors for cardiotoxicity ( current myocardial disease, DM, HTN, dyslipidemia, PAD, smoking, family history of cardiovascular disease)

2- Laboratory work-up: Cardiac biomarkers (Troponin I)

3- Transthoracic Echocardiography: Patients underwent transthoracic echocardiography at the entry visit before starting anticancer drugs and 3,6 and 12 months after the entry visit using EPIQ 7C machine. The probe used was the S5-1 Sector Array Transducer uses 5 to $1 \mathrm{MHz}$ extended operating frequency range. The blood pressure and heart rate during the study were recorded. The following variables were obtained: LV ESD (mm), LV EDV(ml), LV $\mathrm{ESV}(\mathrm{ml}), \mathrm{E} / \mathrm{A}$ Ratio, DT (ms), IVRT (ms), Mitral e`average, E/e' , LA diameter(mm), LV EF (\%), and GLS (\%).

\section{RESULTS}

In this study 100 breast cancer patients aged $\geq 18$ years old included, mean height $156 \pm 7 \mathrm{~cm} 2$, mean weight $72 \pm 14 \mathrm{~kg}$, BMI $29 \pm 6 \mathrm{~kg} / \mathrm{m} 2$. Three cases died before completion of chemotherapy.

A total of 97 patients, 91/97 (93\%) receive chemotherapy ,75/97(77\%) of them underwent radiotherapy after chemotherapy, 71/97 (73\%) take hormonal treatment . 34 patients (35\%) had a history of hypertension and 28 patients (29\%) had a history of diabetes, and one patient (1\%) had history of ischemic heart disease, which were well controlled by medication. No participant reported symptoms of cardiac failure during the anticancer therapy.

Follow up troponin test and echocardiography were performed 3 months, 6months \&12 months after baseline study. No patients developed significant valvular or pericardial disease during our study. In this study all patients were troponin negative (the cut off value was $0.50 \mathrm{ng} / \mathrm{ml}$.). Clinical and echocardiographic parameters during this study are listed in Table1.

Table 1: Clinical and Echocardiographic parameters.

\begin{tabular}{|l|l|l|l|l|l|}
\hline & $1^{\text {st }}$ & $\begin{array}{l}3 \mathrm{mo} \\
\text { visit }\end{array}$ & $\begin{array}{l}6 \\
\text { nths }\end{array}$ & $\begin{array}{l}12 \mathrm{~m} \\
\text { mont }\end{array}$ & $\begin{array}{l}\text { P- } \\
\text { onth }\end{array}$ \\
\hline
\end{tabular}




\begin{tabular}{|c|c|c|c|c|c|}
\hline & & visit & $\begin{array}{l}\text { hs } \\
\text { visit }\end{array}$ & $\begin{array}{l}\mathrm{s} \\
\text { visit }\end{array}$ & \\
\hline HR & $78 \pm 1$ & $80 \pm 9$ & $80 \pm 1$ & $81 \pm 1$ & 0.2035 \\
\hline (bp & 0.9 & .7 & 0.3 & 1.7 & $24(\mathrm{NS})$ \\
\hline \multicolumn{6}{|l|}{ m) } \\
\hline SBP & $120 \pm$ & $120 \pm$ & $121 \pm$ & $121 \pm$ & 0.5754 \\
\hline$(\mathrm{mm}$ & 19 & 18.6 & 17.8 & 15.2 & $02(\mathrm{NS})$ \\
\hline \multicolumn{6}{|l|}{$\mathrm{Hg}$ ) } \\
\hline DBP & $75 \pm 1$ & $75 \pm 1$ & $76 \pm 1$ & $77 \pm 9$ & 0.5209 \\
\hline$(\mathrm{mm}$ & 1.3 & 0.3 & 0.6 & .7 & $64(\mathrm{NS})$ \\
\hline \multicolumn{6}{|l|}{$\mathrm{Hg}$ ) } \\
\hline $\begin{array}{l}\mathrm{LV} \\
\end{array}$ & $30 \pm 3$ & $31 \pm 3$ & $32 \pm 3$ & $33 \pm 3$ & $<0.000$ \\
\hline $\begin{array}{l}\text { ESD } \\
(\mathrm{mm}\end{array}$ & .3 & .3 & & & \\
\hline ) & & & & & \\
\hline LV & 68.2 & 70.8 & 72.8 & 72.7 & 0.0006 \\
\hline EDV & \pm 14 & \pm 16 & \pm 15 & \pm 14 & $09(\mathrm{~S})$ \\
\hline (ml) & 1 & 1 & 4 & 3 & \\
\hline LV & 22.6 & 27.6 & 28.4 & 26.6 & $<0.000$ \\
\hline ESV & \pm 5.2 & \pm 7.2 & \pm 9.7 & \pm 6.3 & $1(\mathrm{~S})$ \\
\hline (ml) & & & & & \\
\hline $\bar{E} / \mathrm{A}$ & 0.93 & 0.84 & 0.84 & 0.79 & $<0.000$ \\
\hline Rati & \pm 0.2 & \pm 0.1 & \pm 0.2 & \pm 0.1 & $1(\mathrm{~S})$ \\
\hline o & 2 & 4 & 2 & 8 & \\
\hline DT & $211 \pm$ & $218 \pm$ & $217 \pm$ & $227 \pm$ & $<0.001$ \\
\hline (ms) & 34.9 & 32.6 & 39.2 & 37.5 & 717(S) \\
\hline IVR & $82 \pm 1$ & $85 \pm 1$ & $83 \pm 1$ & $84 \pm 1$ & 0.4742 \\
\hline $\mathrm{T}$ & 4.7 & 4.2 & 3.8 & 3.5 & $03(\mathrm{NS})$ \\
\hline (ms) & & & & & \\
\hline
\end{tabular}

\begin{tabular}{|l|l|l|l|l|l|}
\hline $\begin{array}{l}\text { Mitr } \\
\text { al } \\
\text { e`av } \\
\text { erag } \\
\text { e }\end{array}$ & $8 \pm 1$. & $8 \pm 1$. & $8 \pm 1$. & $8 \pm 1$. & $<0.000$ \\
\hline $\begin{array}{l}\text { E/e } \\
\text { ( }\end{array}$ & $8 \pm 1$. & $7 \pm 1$. & $7 \pm 1$. & $7 \pm 1$. & 0.0397 \\
\hline $\begin{array}{l}\text { LA } \\
\text { eter } \\
(\mathrm{mm}\end{array}$ & $31 \pm 3$ & $32 \pm 2$ & $33 \pm 2$ & $34 \pm 2$ & $<0.000$ \\
\hline $\begin{array}{l}\text { LV } \\
\text { EF }\end{array}$ & $66 \pm 3$ & $60 \pm 4$ & $62 \pm 4$ & $63 \pm 4$ & $<0.000$ \\
$(\%)$ & .4 & .5 & .6 & $1(\mathrm{~S})$ \\
\hline GLS & - & - & - & - & $1(\mathrm{~S})$ \\
$(\%)$ & $22 \pm 1$ & $20 \pm 1$ & $20 \pm 2$ & $20 \pm 2$ & $1(\mathrm{~S})$ \\
\hline
\end{tabular}

$\mathrm{HR}=$ heart rate; $\mathrm{SBP}=$ systolic blood pressure; $\mathrm{DBP}=$ diastolic blood pressure; LV $\mathrm{ESD}=1 \mathrm{eft}$ ventricular end systolic diameter; LVEDV = left ventricular end diastolic volume; LVESV = left ventricular end systolic volume; $\mathrm{DT}=$ deceleration time; IVRT $=$ isovolumetric relaxation time; $\mathrm{LA}=$ left atrium; $\mathrm{LVEF}=$ left ventricular ejection fraction; GLS = global longitudinal strain. NS=non-significant, $S=$ significant.

1-this study revealed that Left ventricular end systolic volume increase significantly after anticancer therapy ( P-value $=$ $<0.0001$ ) 


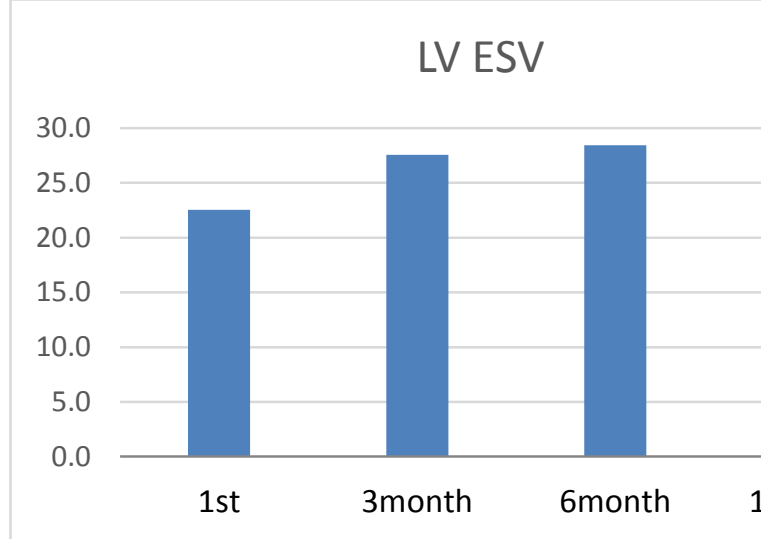

anticancer therapy. (P-value = $<0.0001$ )

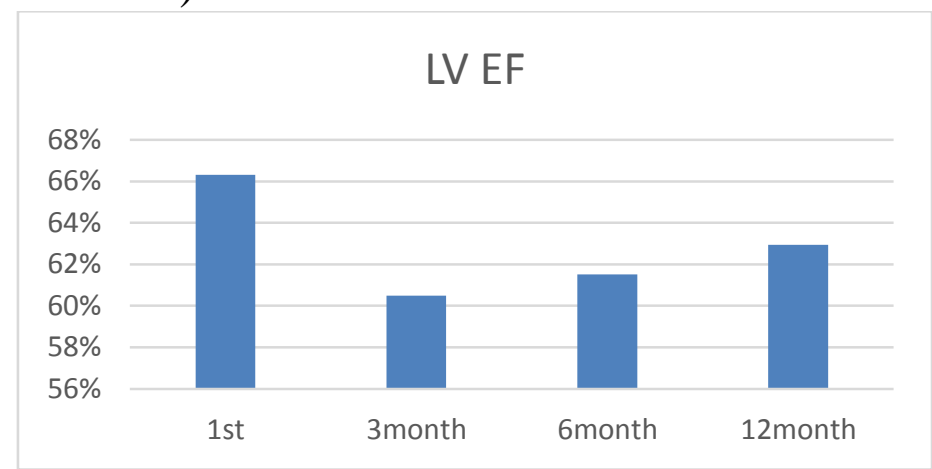

2-this study shows that Left ventricular end diastolic volume increase significantly after anticancer therapy (Pvalue $=0.000609$ )

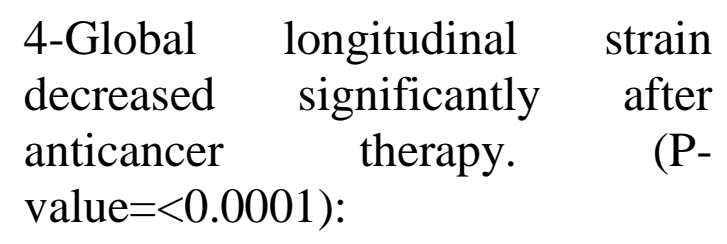

4-Global longitudinal strain decreased significantly after anticancer therapy. (Pvalue $=<0.0001$ ):
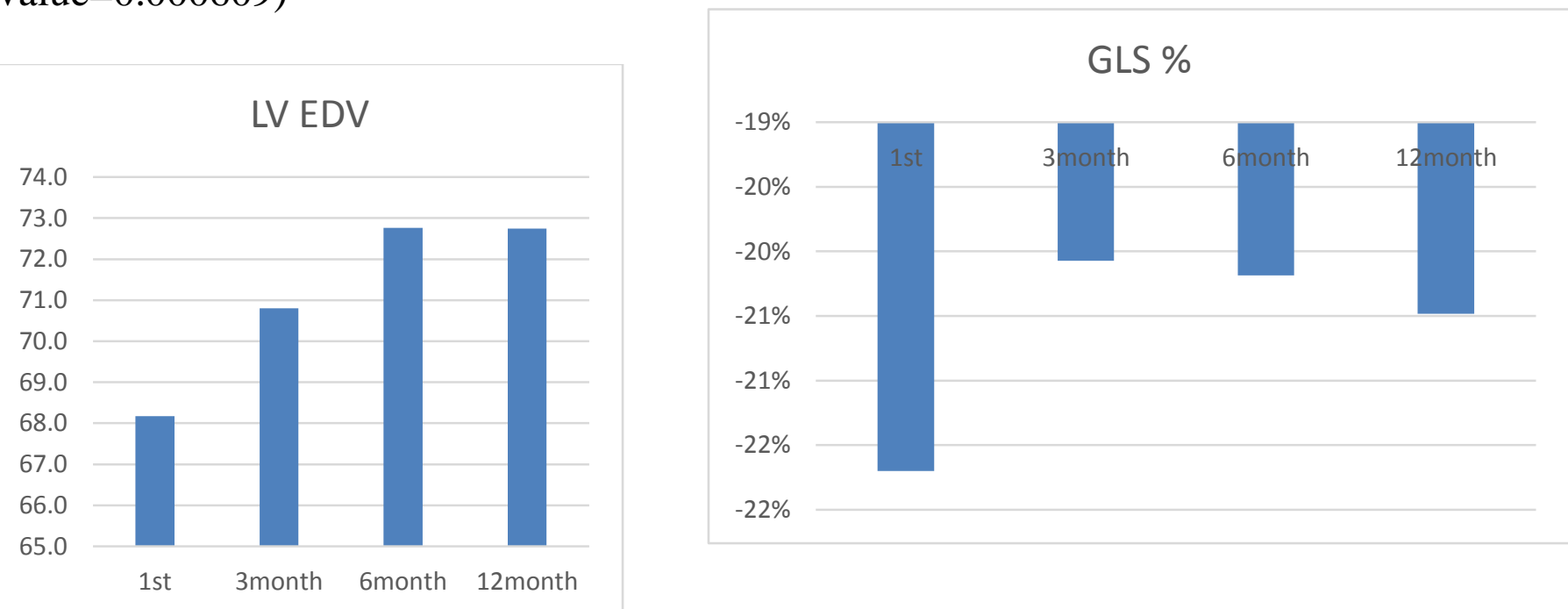

5-this study revealed that the incidence of subclinical LV dysfunction by GLS has a significant Linear negative correlation with the percentage change in LVEF ( $\mathrm{p}$-value = $<0.0001$ )

3- the study revealed that Left ventricular ejection fraction decreased significantly after 


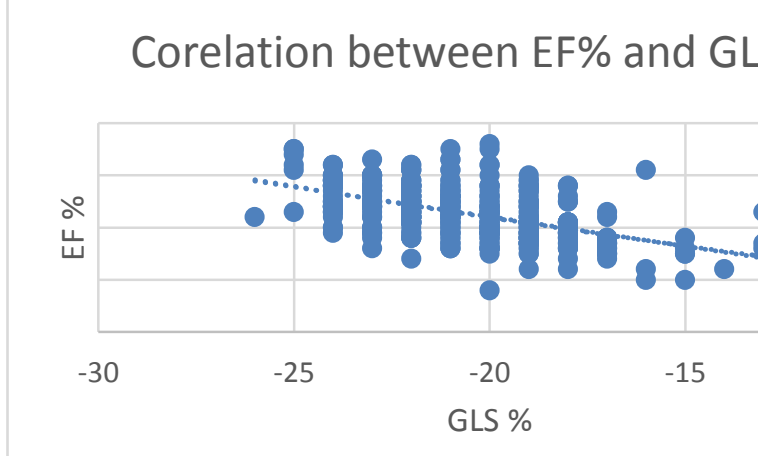

7-LA diameter $(\mathrm{P}$-value $=<0.0001)$ significantly increase post anticancer therapy .

8-Diastolic parameters are listed in Table 1. $\mathrm{E} / \mathrm{A}$ ratio $(\mathrm{P}$-value $=<0.0001)$, Mitral $\mathrm{e}^{\prime}$ average $(\mathrm{P}-$ value $=<0.0001)$ and $\mathrm{E} / \mathrm{e}$ $(\mathrm{P}$-value $=0.039712)$ were significantly reduced post anticancer therapy, Deceleration Time $(\mathrm{P}$-value $=$ $<0.001717)$ significantly increase post anticancer therapy, IVRT $(\mathrm{P}$-value $=$ 0.581363) none significantly reduced post anticancer therapy.

Diastolic function grade was more prevalent with `impaired diastolic function' increasing from $61 \%$ to $84 \%$ in 3 months visit, $81 \%$ in 6 months visit and $91 \%$ in 12 months visit (p-value $<0.001$ ) and normal diastolic function decreasing from $39 \%$ to $15 \%$ in 3 months visit, $7 \%$ in 6 months visit and 3\%in 12 months $\operatorname{visit}(p<0.001)$. pseudo normal diastolic function increasing from $0 \%$ to $11 \%$ in 3 months visit, $11 \%$ in 6 months visit and 6\% in 12 months visit $(\mathrm{p}<0.001)$.

\section{Diastolic Dysfuction}

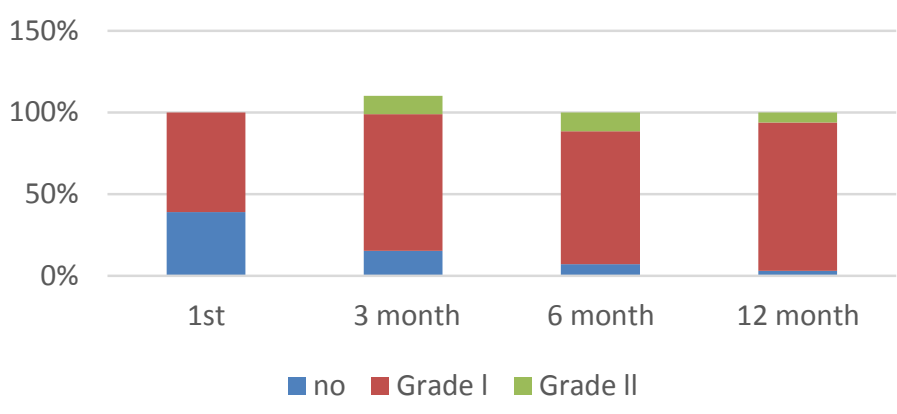

\section{DISCUSSION}

This study was aimed at assessing the incidence of breast cancer treatment-induced cardiotoxicity. In 2016, the European Society of Cardiology has published a position paper recommending the diagnosis of cardiotoxicity be made in the presence of an ejection fraction (EF) reduction $>10 \%$ for values below lower limit of normal. ${ }^{9}$

Cardiotoxicity is a well-established side effect of several anti-neoplastic drugs, particularly anthracyclines, trastuzumab and radiation therapy to the thorax used for breast cancer treatment. ${ }^{10,11}$ Global longitudinal strain (GLS) is used in clinical practice aimed at the early detection of changes in myocardial contractile function. ${ }^{12}$ However, neither GLS use nor its cutoff point to predict cardiotoxicity have been standardized. The American Society of Echocardiography and the 
European Association of

Cardiovascular Imaging have agreed that deformity changes precede ventricular dysfunction. A reduction $>15 \%$ in GLS, immediately after or during anthracycline treatment, was the most useful parameter to predict cardiotoxicity, while a reduction < $8 \%$ might exclude its diagnosis. ${ }^{13}$ However, there is a grey zone between those values.

\section{CONCLUSION:}

- The results of the present study showed that the imaging in the form of Left Ventricular EF and GLS was a good predictor for cardiotoxicity in our population, with high efficacy for its early diagnosis.

- The incidence cardiotoxicity associated with the antineoplastic treatment for breast cancer was $14 \%$ in our study.

- A significant LV GLS drop was observed from the third month onward.

- Longer term follow-up is needed to determine the clinical importance of these early findings.

\section{ABBREVIATIONS:}

CVD cardiovascular disease

DM diabetes mellitus

DT deceleration time;

EDV end diastolic volume

ESV end systolic volume

GLS global longitudinal strain

HF heart failure

HTN hypertension

IVRT isovolumetric relaxation time;

LV left ventricle

LV EF left ventricular ejection fraction

LA left atrium

PAD peripheral artery disease

\section{REFERENCES;}

1) Siegel R, Naishadham D, Jemal A. Cancer statistics, 2012. CA Cancer J Clin. 2012; 62:10-29.

2) Jones LW, Haykowsky MJ, Swartz $\mathrm{JJ}$, et al. Early breast cancer therapy and cardiovascular injury. J Am Coll Cardiol. 2007; 50:1435-41.

3) Brower V. Cardiotoxicity debated for anthracyclines and trastuzumab in breast cancer. J Natl Cancer Inst. 2013; 105:835-6.

4) Telli ML, Witteles RM. Trastuzumab-related cardiac dysfunction. J Nat 1 Compr Canc Netw. 2011; 9:243-95.

5) Lancellotti P, Nkomo VT, Badano LP, et al: Expert consensus for multi- 
modality imaging evaluation of cardiovascular complications of radiotherapy in adults: a report from the European Association of Cardiovascular Imaging and the American Society of Echocardiography. Eur Heart J Cardiovasc Imaging 2013; 14: 721740.

6) Negishi K, Negishi T, Hare JL, et al. Independent and incremental value of deformation indices for prediction of trastuzumab-induced cardiotoxicity. J Am Soc Echocardiogr. 2013; 26:493-8.

7) Yoon GJ, Telli ML, Kao DP, et al. Left ventricular dysfunction in patients receiving cardiotoxic cancer therapies are clinicians responding optimally? J Am Coll Cardiol. 2010; 56:1644-50.

8) Negishi K, Negishi T, Haluska BA, et al. Use of speckle strain to assess left ventricular responses to cardiotoxic chemotherapy and cardioprotection. Eur Heart J Cardiovasc Imaging. 2013 Sep 20.

9) Zamorano JL, Lancellotti P, Rodriguez Muñoz D, et al; Authors/Task Force Members; ESC Committee for Practice Guidelines (CPG). 2016. ESC Position Paper on cancer treatments and cardiovascular toxicity developed under the auspices of the ESC Committee for Practice Guidelines. Eur Heart J. 2016;37(36):2768-801.

10) Billingham ME, Mason JW, Bristow MR, et al.. Anthracycline cardiomyopathy monitored by morphologic changes. Cancer Treat Rep. 1978;62(6):865-72.

\section{1) Force T. Introduction to} cardiotoxicity review series. Circ Res. 2010;106(1):19-20. doi: 10.1161/CIRCRESAHA.109.210724.

12) Tan $T$, Bouras $S$, Sawaya $H$,et al. Time trends of left ventricular ejection fraction and myocardial deformation indices in a cohort of women with breast cancer treated with anthracyclines, taxanes, and trastuzumab. J Am Soc Echocardiogr. 2015;28(5):509-14.

13) Plana JC, Galderisi M, Barac A, et al. Expert Consensus for multimodality imaging evaluation of adult patients during and after cancer therapy: a report from the American Society of Echocardiography and the European Association of Cardiovascular Imaging. J Am Soc Echocardiogr. 2014;27(9):911-39. 